\title{
Research on Public Acceptance of Waste Safety Disposal Based on Structural Equation Model \\ Li Liao $^{a}$, Xiaohua Yang ${ }^{b}$, Yaping Wan ${ }^{b *}$ \\ School of Nursing, University of South China, China \\ ${ }^{\mathrm{b}}$ School of Computer Science and Technology, University of South China, China \\ *Corresponding author: Yaping Wan, Ph.D, ypwan@aliyun.com
}

\begin{abstract}
Waste disposal is one of the noticeable problems in the development of nuclear energy and the use of nuclear technology. The public's awareness about environment and safety was significantly improved. Especially after Fukushima, the public is more sensitive to the development of nuclear energy, and more concerned about the guarantee of nuclear safety. Through screening the impact factors of existing research and according to the existing causal relationship hypothesis, the public acceptance of waste disposal evaluation model is established. According to the significant factors of influencing public acceptance, some countermeasures and suggestions of raising public acceptance are proposed.
\end{abstract}

Key words: public acceptance; waste disposal; public participation; structural equation model; emergency system

\section{Introduction}

Waste safety disposal has aroused public attention all over the world in the development of nuclear energy. Geological disposal is considered to be the most prospect of engineering disposal solution. "Geological disposal" refers to underground stability geological structure (usually in the hundreds of meters or more deep below the surface) of solid radioactive waste disposal facilities, which is to make the long-term effective isolation of radioactive waste and the biosphere. That the public most concerned about are nuclear safety management system is perfect or not, and whether the measures are taken effectively or not, and whether can make sure there will be no nuclear accident. In China, the public's communication in nuclear energy has the following characteristics: (1)unexpectedness of event; (2) difficulty of disposal; (3)severity of result; (4) profound of influence; (5) high sensitivity of social.

In 2006, Chinese government had proposed a general idea of waste geological disposal. However, due to the complexity and uncertainty of waste geological disposal, some problems still have emerged, which has led some nation plans or project implementation to stagnation and repetition. Investigating the reason, it mainly has the following aspects.

First of all, some countries lack the communication with the public in decision-making processes. The public lack of adequate understanding and trust about waste geological disposal, therefore, it failed to gain public's trust and support. Secondly, since the 1990s, the public and the society put forward some new requirements for the waste geological disposal in the aspects of technology, safety and social ethics, and some new ideas also have emerged, which need to have enough time to study and testily. It is also stated that increasing the public acceptance need to adequately communicate with the public. Government should spend a lot of time carrying out publicity, and establish a mechanism to consider the public's interest. The social science survey of the citizens to vote on the waste geological disposal in foreign 
countries shows that public acceptance activities can only be carried out in a step by step, and too hurry or fast is not conducive to promoting the waste disposal work.

In October 2012, China's State Council had approved the "Twelfth Five Year Plan for nuclear safety and radioactive pollution prevention and control" and "the 2020 Vision". The plan clearly put forward to deepen the public participation, and enhance the research field of social confidence.

\section{Backgrounds}

Although the study of waste geological disposal began in the fifty of the last century, a large scale of research work was carried out in various countries in the eighty of the last century. Over the past 30 years, the research on geological disposal over the world has reached more and more climaxes, such as in Finland and the United States, waste disposal sites have initially recognized by the government in 2001 and 2002 respectively. Currently, there are a total of 104 nuclear reactors are running in the United States, producing about 20\% of the national electricity, and 29 nuclear reactors have been shut down. In 2010, the Obama government decided to terminate the Yucca Mountain project and established the Blue Ribbon Committee (BRC) to find a new solution to solve the problem for Yucca Mountain. The reasons for the termination are as follows.(1)Underestimate the power of social opposition and technical risks of Yucca mountain project;(2)Wrongly put the eggs of success in one Yucca mountain basket;(3)High belief in the power of organ authority. As a result, Yucca Mountain was defeated in the face of the power of the social opposition and technical risks. The government has decided to withdraw the application for permission to Yucca Mountain. ${ }^{1}$

South Korea, which has 4 nuclear power plant and a total of 20 units in operation at present, is one of the nuclear power developed countries in the world. Kori nuclear power plant has 6 units of pressurized water reactor. Yonggwang nuclear power plant has 4 units and Ulchin nuclear power plant has 6 units, producing about $40 \%$ of the national electricity. Currently, South Korea is building 8 units of PWR and plans to build 4 units. In order to obtain the nuclear waste disposal site, South Korea has the past nearly 20 years of painful experiences (from 1986 to 2005). All of Korea's efforts and attempts have failed since 1986.The reasons for the failure of the site selection are as follows. (1) The public's concern about the safety of waste disposal facilities; (2) Lack of transparency and stakeholders participate in decisionmaking; (3) Public's confidence in the lack of incentives. Based on the above mentioned reasons, the minister of the knowledge economy has announced a new approach to site selection. The Korean government has thoroughly investigated the site selection of longevity intermediate-level radioactive waste disposal site. As a result, the Ministry of knowledge economy formed the site selection committee for ensuring the transparency and fairness of the site selection process. The committee consists of 17 civilian experts from different fields to manage and supervise the whole process. ${ }^{2}$

It can be seen from above the waste geological disposal of the public participation had the successful experience, but also faced numerous problems, and some countries even last for many years because of the reasons for public participation. Site selection process is stagnant, and some countries take a lot of detours. 
Firstly, the public lack adequate understanding and trust about waste geological disposal. It is mainly the implementation of the department and the public communication is not enough and the transparency of the work plan is not enough, at the same time, due to the past some nuclear accidents. Therefore, the public is also worried about high level radioactive waste disposal. For instance, Switzerland's Wellenberg candidate site selection and Sweden's 2 candidate site selection were rejected in a referendum. Another example, in the 1980s, Japan intended to the candidate site of the high level radioactive waste disposal site in the vicinity of Hokkaido, also because of the public's opposition, the candidate site plan was forced to run into the ground. This situation has continued until today. Therefore, Japan has not yet found candidate site selection of waste disposal site that is acceptable to the public. Another example, American in the Yucca Mountain site selection process, before the president and the Congress make a final confirmation, it had been the opposition of the state government and the local community. Finally, the French Vienne underground laboratory site is from the beginning of 1994, but also due to the public's opposition, was forced to cancel the research work in 1998.

Secondly, the relevant technology has shortage. For instance, to Britain's Sellafield underground laboratory candidate site, although Nirex has carried out a lot of research on the surface and deep drilling, the original plan for deep mountain project, because of the fierce debate on the technology between supporters and opponents, finally led to be put down.

Thirdly, some new ideas have emerged in the research and development of high level radioactive waste disposal, which need adequate time to study and testify, such as the disposed waste of extraction, separation and transmutation, the impact of technology on disposal, as well as the disposal of the safety period is 10 thousand years or longer. For instance, France is ready to spend 15 years to research about the temporary storage, separation and evolution, and special disposal. However, France will not make final decisions on nuclear waste management by 2006.

Finally, due to the political influence, the research and development plan is aborted. For instance, about Germany's Konrad underground laboratory site, its research work is started from the beginning of 1982, due to the political reason, stop running after 1998.

Based on the above situation, in "ten years progress of international radioactive waste geological disposal", OECD/NEA summarized the experience and lessons: "The lack of the public's trust is the main reason for delay of the plan and the biggest obstacle to the implementation of the deep geological disposal". "Most of the execution units expecting and looking forward to the start of deep disposal repository time were postponed than ten years ago". "The reason for the delay is that the technical and scientific progress has shortage and is more difficult to be accepted by the public and the policy". "It is said that the British plan has been retrograde for decades due to the failure of public consultation. Because of the failure of the public vote in Switzerland, the low-medium radioactive waste geological disposal plan has been delayed for many years. The ambitious plans of Sweden and the United States have been delayed for several years, while the uncertainties in the development have led the Canadian proposal to delay for several years, even decades ".

Although some countries lack public trust, no country give up or suspend nuclear waste geological disposal decision-making and still insists that the waste deep geological disposal is the only feasible way to isolate the longevity waste and living environment. Therefore, 
governments have adopted an effective measure to gain the trust and support from the public and the stakeholders. These measures are as follows: ${ }^{3-11}$

(1)Establish an information center and related websites as a channel for communication among the executive department, the public and local community. Such as ONDRAF/NIRAS in Belgium build an information center, and Czech is also the case.

(2)Organize the public to visit the underground laboratory, disposal sites and other nuclear waste disposal research and development facilities.

(3)Organize the public participate in the site selection process, participate in the evaluation and safety analysis of the environment, participate in the government's decision-making.

(4)Hold hearings, seminars. It is quite popularly in foreign countries, such as United States,

Czech and other countries are done so in the course of the site selection.

(5)In order to increase transparency, it is necessary to publish the relevant materials to the public, such as site selection plan, site selection criteria, environmental assessment report, safety analysis report, etc.

(6)To issue a notice to the municipal authorities and inform the executive branch of the proposed project, in which invite the public to participate in the information seminar, and put forward opinions and suggestions on the site selection process. It's done in Hungary.

(7)Set up public organizations and supervise the implementation of the research activities of the department. For example, Hungary forms an organization called "social control and joint". (8)To carry out various related exhibitions and film and television show activities. Such activities are carried out in many countries, such as United States’s Yucca Mountain.

(9)"Voluntary municipal administration public application". This is a way the Japanese adopted the voluntary disclosure of the site selection.

(10)Establish compensation or incentive mechanism.

In a word, from the above analysis, we can conclude that some countries are trying their best to strive for a wider public to participate in the site selection process, and to strengthen communication with the public. In China, that the public have vague understanding of nuclear power is quite common. China's existing three nuclear power stations in the initial stage of construction have encountered considerable resistance. Qinshan nuclear power station has been rejected by local government and some people in 1981. Daya Bay nuclear power station had been protested by millions of people in Hong Kong. The construction of Tianwan nuclear power plant was able to resume because of the replacement of local leadership and changing the name of the nuclear power plant. ${ }^{12}$ The project of Jiangmen is located in Guangdong which is invested about 40 billion. In July 2013, because the project is not enough to communication with the public, it led to serious opposition by the local public. So the project had to suspend. ${ }^{13}$ The state plans to build Bailong nuclear power plants about $40 \mathrm{~km}$ from the Fangchenggang nuclear power plant. Fangchenggang City People's Congress asks a higher lift Bailong nuclear power project cooperation framework agreement. A radiation device took place in the event of a cobalt source in Qixian, due to the lack of public communication and relevant knowledge leading local people to run away. It is very important to strengthen the publicity of nuclear and radiological aspects of knowledge. On August 11, 2014, some persons think Harbin has a nuclear power plant incident. As can be seen from the above, the public acceptance of nuclear power also has some problems. China is currently in the early 
stages of waste geological disposal work. How to make the public understand the geological disposal of waste and improve the transparency of the decision-making process is the key.

\section{Design of public acceptance model}

\subsection{Overall technical architecture}

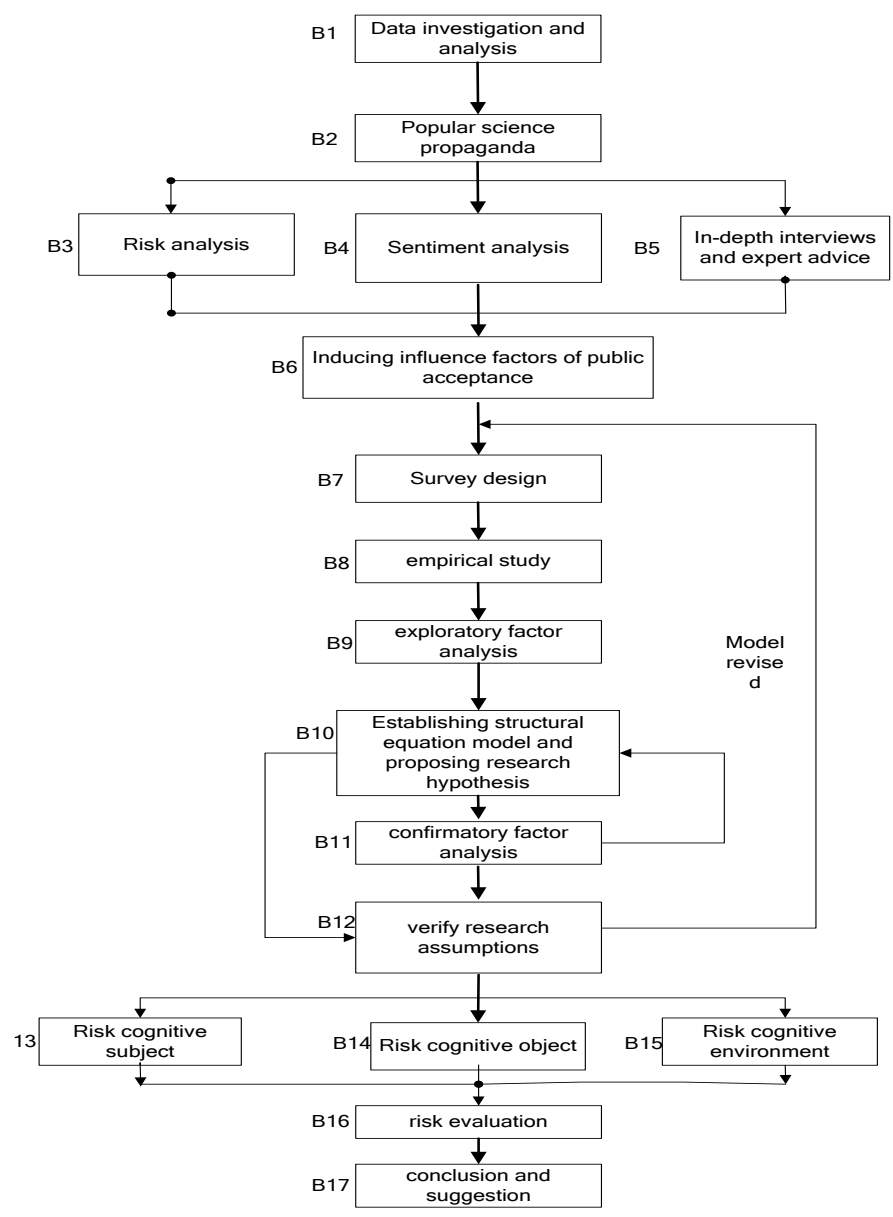

Fig. 1 The technology architecture of public acceptance model

In the process of waste disposal (including site selection process) the public and relevant stakeholders to participate is very important. As an important preliminary work, it is very necessary and urgent to carry out research on public investigation and evaluation technology of waste site. We use structural equation model(SEM) to establish public acceptance model of waste disposal, meanwhile, combine normative research and empirical analysis, exploratory factor analysis and confirmatory factor analysis and other research methods. Fig. 1 shows the overall technical architecture. From B1 to B17 the nineteen boxes represent the overall technical architecture we established public acceptance model. About B1 and B6, on the foundation of the previous literatures, On-the-spot investigation and expert consultation program, the questionnaire is designed. Using software to exploratory analysis the questionnaire samples data, and concludes that the acceptance influence factors are perceived usefulness, risk perception, compensation rationality, trust etc. The factors for trust are the principle of site selection and matching management. We provide advises and countermeasures for improving the public acceptance and trust level of sit selection. The 
government and some related departments should make the matching management in sit selection.

(1)First of all, we carry out popular science propaganda for waste disposal, so that the public understand relevant national laws and regulations and industry standards, familiar with the process of waste geological disposal, methods and emergency response measures.

(2) In this paper, risk theory is applied to the analysis of the influence factors of public acceptance.

(3) An empirical study is conducted in the form of field research, in-depth interviews and questionnaire surveys. Through investigation and data collecting, reveal the essence of problem. At the same time, with the questionnaire survey, the public has a wide range of issues related to the geological disposal of waste.

(4) Based on relevant theoretical basis of public acceptance, this paper uses a structural equation model to build public acceptance model. An empirical analysis based on questionnaire survey data and related statistical software was used to revise the model.

(5) Based on exploratory analysis, initial hypothesis model was established. Confirmatory analysis was carried out on the study, and verified and modified model and hypotheses.

(6) Combined with investigation and analysis results, according to theory of risk perception and decision-making, from three aspects, object of risk cognition-technology, environment of risk cognition-trust, subject of risk cognition-communication, the ways to improve public acceptability of waste geological disposal are discussed.

\subsection{Public acceptance initial model based on structural equation}

The factors that are intended to consider the impact on public about geological disposal of waste acceptance include usefulness and risk of perceived waste disposal, trust in government and technology department, giving reasonable compensation to the public. Measuring factors on trust of public on disposal of waste are summarized as six dimensions, respectively as social justice, information opening, public participation, interaction among stakeholders, demonstration of existing engineering projects, risk controllability. Based on the analysis and summary of research at home and abroad, initial model of waste disposal of the public acceptance can be drawn as fig. 2 .

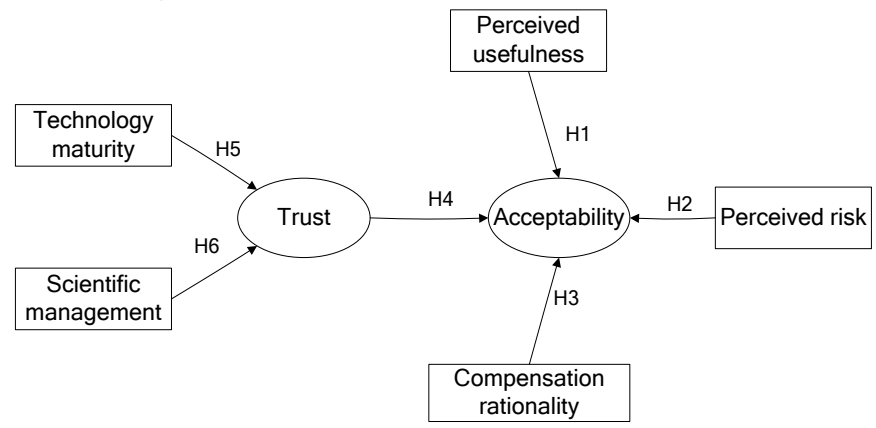

Fig. 2 The initial model of Waste disposal public acceptance

In order to validate the model and to ensure the accuracy of the model we propose the following hypothesis.

H1: Public perception usefulness to waste disposal has a positive impact on public acceptance.

$\mathrm{H} 2$ : Public risk perception to waste disposal has a negative impact on public acceptance.

H3: The rationality of compensation has a positive effect on public acceptability. 
H4: Public trust in government and technology department has a positive impact on public acceptance.

H5: Maturity of waste geological disposal technology has a positive impact on trust.

H6: Scientific management in the process of waste disposal has a positive impact on trust.

\section{Countermeasures and suggestions on improving public acceptance}

This paper builds public acceptance evaluation model and analyses the factors that have a significant impact to public acceptance. According to these factors, some countermeasures and suggestions are put forward to improve public acceptance. Further, risk identification and risk estimation can be carried out for these factors. Some suggestions to be considered are as follows.

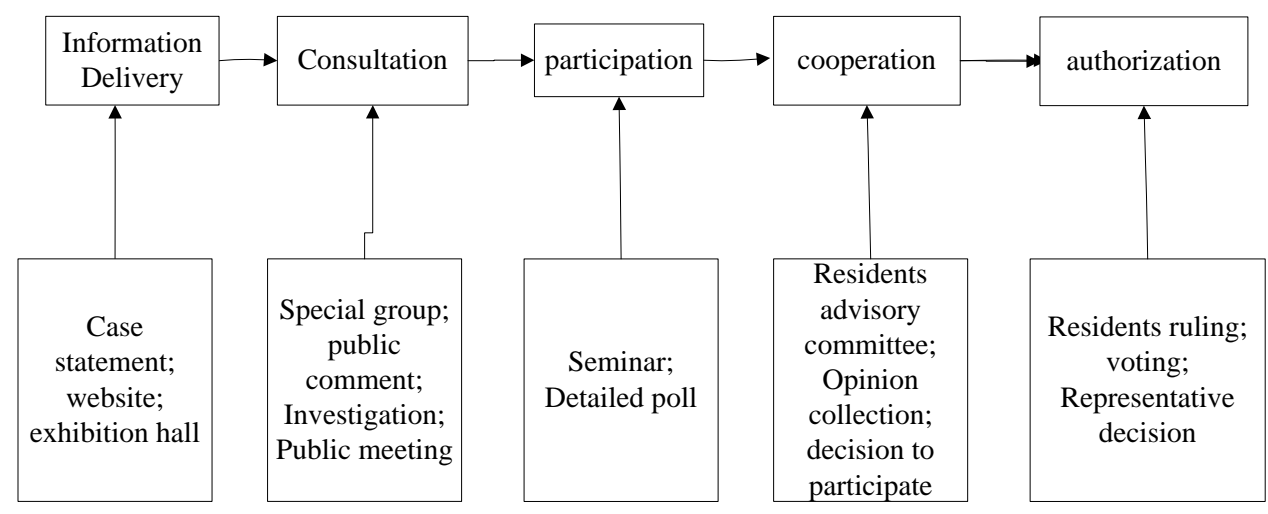

Fig. 3 Public participation map in the establishment of International Association

1) Environmental risk assessment and control mechanism. The site of waste geological disposal which is NIMBY (Not In My Back Yard) is getting more and more difficult. The main reason lies in its risk. How to assess and reduce risk to not affecting people's lives and health conditions that requires environmental risk assessment and risk control mechanisms. This needs to be considered and designed from the scientific level of waste disposal technology and waste management.

2) Information disclosure and public participation mechanism. International Association for public participation (IAP2) builds Public participation knowledge map which is showed as Fig. 3. Public participation way from left to right is gradually in-depth. In the whole process of decision making, government and the relevant departments are working directly with the public. Through seminars alternative solutions are developed and solutions are identified to ensure that the problem of public concern and hope that can be truly understood and considered. And as much as possible to put public opinion into the process of decisionmaking

3) Establishment of emergency mechanism. Emergency system refers to the government and other public institutions in the event of emergency prevention, the incident response, unexpected emergency disposal of social security and handling public crisis. Through building the necessary coping mechanisms, it takes a series of necessary measures to protect the public safety, and promote social harmony and healthy development. In the process of geological disposal, environmental emergency response mechanism should be established to provide protection to deal with the problem in time and to improve the public's confidence.

4) Compensation mechanisms. Studies have shown that reasonable compensation plays an important role in the construction of "neighbourhood avoid" facility. In order to improve the 
public acceptance compensation is to use direct economic benefits or indirect way to compensate the economic loss of the surrounding residents and to reduce the residents' struggle and residents' sense of injustice. Compensation is generally divided into two categories which are direct compensation such as money and other indirect compensation.

\section{Conclusions}

In this paper, the structural equation model is introduced to public acceptance of waste geological disposal and factors which have a significant impact on public acceptance are identified. The reliability of the model is guaranteed by a combination of exploratory and confirmatory methods. By changing qualitative analysis to quantitative representation it can be provided credible decision support for relevant parties about public acceptance of waste geological disposal.

\section{References}

1. P.N. Steven,Centralized intermediate storage: Past, present and future-Overview of United States $\mathrm{h}$ centralized intermediate storage history, Radioactive waste management and nuclear facilities,2013(1):19-24.

2. J.Q. Liu, X.W. Xiong, Radioactive Waste Intermediate Depth Disposal. Radiation protection bulletin, 2012(5):6-10.

3. A. Kjell, W.O. Clas, W. Magnus,et al., Design and Evaluation of Public Hearings for Swedish Site Selection, SKI Report 2003:32.

4. Geological disposal summary report on IPPA(implementing public participation approaches) progress year 2,NDA Technical note NO:18951311,England,2013,2.

5. Public Information, Consultation and Involvement in Radioactive Waste Management An International Overview of Approaches and Experiences, ISBN 92-64-021280,OECD,2003

6. G.Q. Xu, et al. ,Some basic rules for the disposal of high level radioactive wastes. Beijing Geological Research Institute of nuclear industry,1996

7. Community Plan of Action in the Field of Radioactive Waste Management, Radioactive Waste Disposal: Commission of Science, 2005

8. Presentation on US/China Workshop on Radioactive Waste Regulation, Codes, and Standards, 2005

9. P.A. Witherspoon, G.S. Bodvarsson, Geological Challenges in Radioactive Waste Isolation, Third Worldwide Review, LBNL-49767, 2001

10. S.Y.Chu, An Integrated Approch to Nuclear Waste Diposal, Workshop on Performance Assessment for Nuclear Waste Management and Disposal, CSRME, Beijing, 2006

11. C.X. Liu, Studies on the Public Acceptance of Nuclear Energy of China, Tsinghua University,2008

12. Sino French nuclear fuel cycle Symposium papers. Beijing China, 2014, December 10-11.

13. G.J. Li, Adhere to the scientific development, to ensure the safety of nuclear and radiation- interpreted in " nuclear safety- Radioactive pollution prevention and control of the "Twelfth Five Year Plan" and the 2020 Vision objectives,2012 